Acta Crystallographica Section E

Structure Reports

Online

ISSN 1600-5368

S. M. Malathy Sony, ${ }^{a}$ P. Charles, ${ }^{\text {a }}$ M. N. Ponnuswamy, ${ }^{a *}$ H. S. Yathirajan $^{b}$ and M. Nethaji

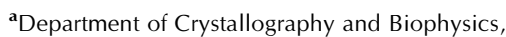
University of Madras, Guindy Campus, Chennai 600 025, India, bepartment of Studies in Chemistry, University of Mysore, Manasagangotri, Mysore 570 006, India, and ${ }^{\mathrm{C}}$ Department of Inorganic and Physical Chemistry, Indian Institute of Science, Bangalore 560 012, India

Correspondence e-mail:

mnpsy2004@yahoo.com

\section{Key indicators}

Single-crystal X-ray study

$T=293 \mathrm{~K}$

Mean $\sigma(\mathrm{C}-\mathrm{C})=0.003 \AA$

$R$ factor $=0.063$

$w R$ factor $=0.151$

Data-to-parameter ratio $=17.5$

For details of how these key indicators were automatically derived from the article, see http://journals.iucr.org/e.

\title{
Ethyl 5-amino-3-methylisoxazole-4-carboxylate
}

The title compound, $\mathrm{C}_{7} \mathrm{H}_{10} \mathrm{~N}_{2} \mathrm{O}_{3}$, is planar and the structure is stabilized by an intramolecular $\mathrm{N}-\mathrm{H} \cdots \mathrm{O}$ hydrogen bond. The molecules form dimers through $\mathrm{N}-\mathrm{H} \cdots \mathrm{O}$ hydrogen bonds that are linked by $\mathrm{N}-\mathrm{H} \cdots \mathrm{N}$ hydrogen bonds along the $c$ axis.

\section{Comment}

Isoxazoles form part of many drugs used for antidepressant therapy (propionic acid derivative) (Skolnick, 2002), and act as antiviral compounds (methyltetrazole derivative; Giranda, 1995), as protein tyrosine phosphatase 1B inhibitors (carboxylic acid derivative; Zhao et al., 2004) and as growth hormone secretagogue receptor (GHS-R) antagonists (carboxamides derivative; Liu et al., 2004). In view of these important properties, the crystal structure of the title compound, (I), is presented here.

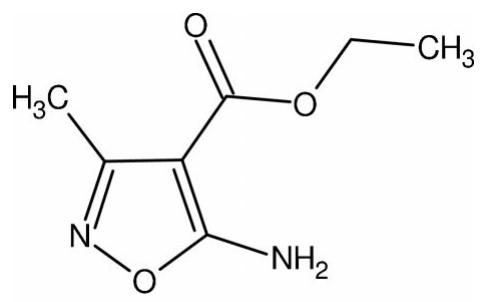

(I)

The isoxazole ring is planar and the ester group attached to it shows an extended conformation, which is observed from the torsion angles $\left[\mathrm{C} 5-\mathrm{C} 4-\mathrm{C} 6-\mathrm{O} 8=-178.73(17)^{\circ}, \mathrm{C} 4-\right.$ $\mathrm{C} 6-\mathrm{O} 8-\mathrm{C} 9=178.88(17)^{\circ}$ and $\mathrm{C} 6-\mathrm{O} 8-\mathrm{C} 9-\mathrm{C} 10=$ $\left.-179.55(18)^{\circ}\right]$. The amine group is in an $s p^{2}$ hybridization state, as seen from the bond angles around it [C5-N11$\mathrm{H} 11 A=121.8(16)^{\circ}, \mathrm{C} 5-\mathrm{N} 11-\mathrm{H} 11 B=118.5(17)^{\circ}$ and $\left.\mathrm{H} 11 A-\mathrm{N} 11-\mathrm{H} 11 B=120(2)^{\circ}\right]$. The methyl, amine and ester substituent groups lie in the plane of the isoxazole ring (Fig. 1).

An intermolecular $\mathrm{N}-\mathrm{H} \cdots \mathrm{O}$ hydrogen bond (Table 1) between amine atom $\mathrm{N} 11$ and carboxylate atom $\mathrm{O} 7$ stabilizes the structure and forms an $S(6)$ pattern (Bernstein et al., 1995). The molecules in the crystal structur are arranged such that interesting hydrogen-bond patterns are observed. A dimer is formed through $\mathrm{N}-\mathrm{H} \cdots \mathrm{O}$ intermolecular hydrogen bonds between amine atom $\mathrm{N} 11$ and carboxylate atom $\mathrm{O} 7\left(\frac{1}{2}-x\right.$, $-\frac{1}{2}-y, 1-z$ ), forming the ring pattern $R_{2}^{2}(12)$ (Fig. 2). These dimers are linked through an $\mathrm{N}-\mathrm{H} \cdots \mathrm{N}$ hydrogen-bonded chain of type $C(5)$ along the $c$ axis, between atoms N11 and $\mathrm{N} 2\left(\frac{1}{2}-x,-\frac{1}{2}+y, \frac{3}{2}-z\right)$. Geometric details of the hydrogen bonds are in Table 1 .
Received 16 December 2004 Accepted 20 December 2004 Online 24 December 2004
(C) 2005 International Union of Crystallography Printed in Great Britain - all rights reserved 


\section{Experimental}

The [3+2]-cycloaddition of a support-bound nitrile oxide with an alkyne or alkene is a useful synthetic route to isoxazoles or isoxazolines, respectively (Shankar et al., 1998). Acetaldehyde (1 M) was treated with a solution of hydroxylamine hydrochloride $(1 M, 0.6 \mathrm{ml})$ in anhydrous pyridine $(50 \mathrm{ml})$ and kept at room temperature for $4 \mathrm{~h}$. The reagent solution was decanted and washed with dimethylformamide (DMF) and dichloromethane (DCM), and then air dried. The resultant oxime was treated with $N$-chlorosuccinimide (NCS, $1.2 \mathrm{M}$ ) to obtain the chlorooxime, and treated with triethylamine (TEA, $5 \mathrm{ml}$ ) and DCM to form a nitrile oxide in situ. The nitrile oxide was then trapped by a dipolarophile (ethyl chloroaminocarboxylate, $1 \mathrm{M}$ ) afford the isoxazole derivative. The product was crystallized from DCM.

$$
\begin{aligned}
& \text { Crystal data } \\
& \mathrm{C}_{7} \mathrm{H}_{10} \mathrm{~N}_{2} \mathrm{O}_{3} \\
& M_{r}=170.17 \\
& \text { Monoclinic, } C 2 / c \\
& a=12.642(2) \AA \\
& b=8.5036(14) \AA \\
& c=16.934(3) \AA \\
& \beta=98.488(3)^{\circ} \\
& V=1800.5(5) \AA^{3} \\
& Z=8
\end{aligned}
$$

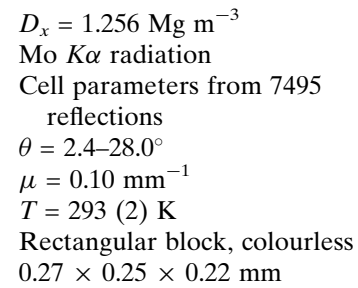

\section{Data collection}

Siemens SMART CCD areadetector diffractometer $\omega$ scans

Absorption correction: none 7495 measured reflections 2070 independent reflections

1494 reflections with $I>2 \sigma(I)$ $R_{\text {int }}=0.027$

$\theta_{\text {max }}=28.0^{\circ}$

$h=-16 \rightarrow 16$

$k=-11 \rightarrow 11$

$l=-18 \rightarrow 22$

\section{Refinement}

Refinement on $F^{2}$

$R\left[F^{2}>2 \sigma\left(F^{2}\right)\right]=0.063$

$w R\left(F^{2}\right)=0.151$

$S=1.14$

2070 reflections

118 parameters

$\mathrm{H}$ atoms treated by a mixture of independent and constrained refinement

Table 1

Hydrogen-bond geometry $\left(\AA,^{\circ}\right)$.

\begin{tabular}{lllll}
\hline$D-\mathrm{H} \cdots A$ & $D-\mathrm{H}$ & $\mathrm{H} \cdots A$ & $D \cdots A$ & $D-\mathrm{H} \cdots A$ \\
\hline $\mathrm{N} 11-\mathrm{H} 11 A \cdots \mathrm{N} 2^{\mathrm{i}}$ & $0.85(3)$ & $2.14(3)$ & $2.981(3)$ & $172(2)$ \\
$\mathrm{N} 11-\mathrm{H} 11 B \cdots \mathrm{O} 7^{\text {ii }}$ & $0.85(3)$ & $2.16(3)$ & $2.915(2)$ & $148(2)$ \\
$\mathrm{N}_{11}-\mathrm{H} 11 B \cdots \mathrm{O} 7^{\text {iii }}$ & $0.85(3)$ & $2.39(3)$ & $2.921(3)$ & $122(2)$ \\
\hline
\end{tabular}

Symmetry codes: (i) $-x+\frac{1}{2}, y-\frac{1}{2},-z+\frac{3}{2}$; (ii) $-x+\frac{1}{2},-y-\frac{1}{2},-z+1$; (iii) $x, y, z$.

All C-bound $\mathrm{H}$ atoms were positioned geometrically $(\mathrm{C}-\mathrm{H}=0.96$ and $0.97 \AA$ ) and allowed to ride on their parent atoms, with $U_{\text {iso }}(\mathrm{H})$ values of 1.2 or 1.5 times $U_{\text {eq }}$ (parent atom). All other $\mathrm{H}$ atoms were identified from a difference Fourier map and refined isotropically.

Data collection: SMART (Siemens, 1996); cell refinement: SAINT (Siemens, 1996); data reduction: $S A I N T$; program(s) used to solve structure: SHELXS97 (Sheldrick, 1997); program(s) used to refine structure: SHELXL97 (Sheldrick, 1997); molecular graphics: PLATON (Spek, 2003), ORTEP-3 (Farrugia, 1997) and ZORTEP (Zsolnai, 1998); software used to prepare material for publication: PLATON).

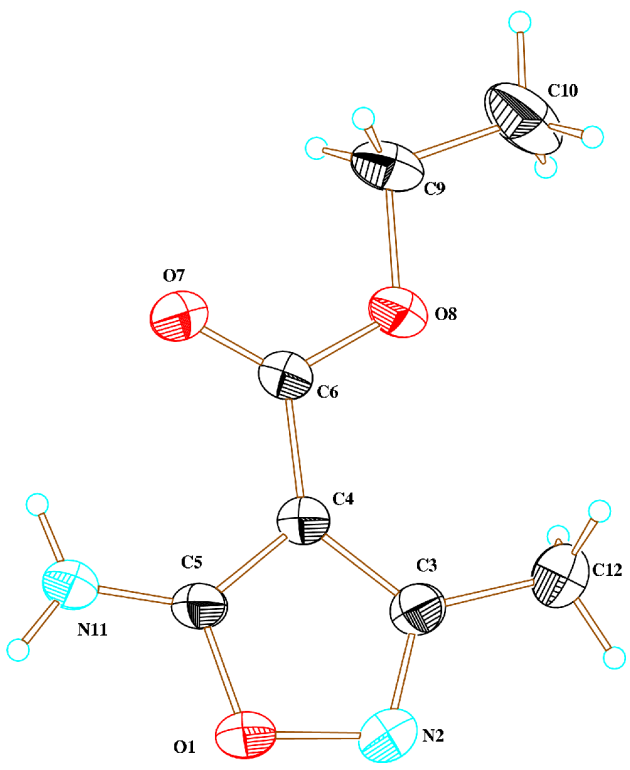

Figure 1

ZORTEP (Zsolnai, 1998) plot of the molecule, with the atomic numbering scheme. Displacement ellipsoids are drawn at the $30 \%$ probability level.

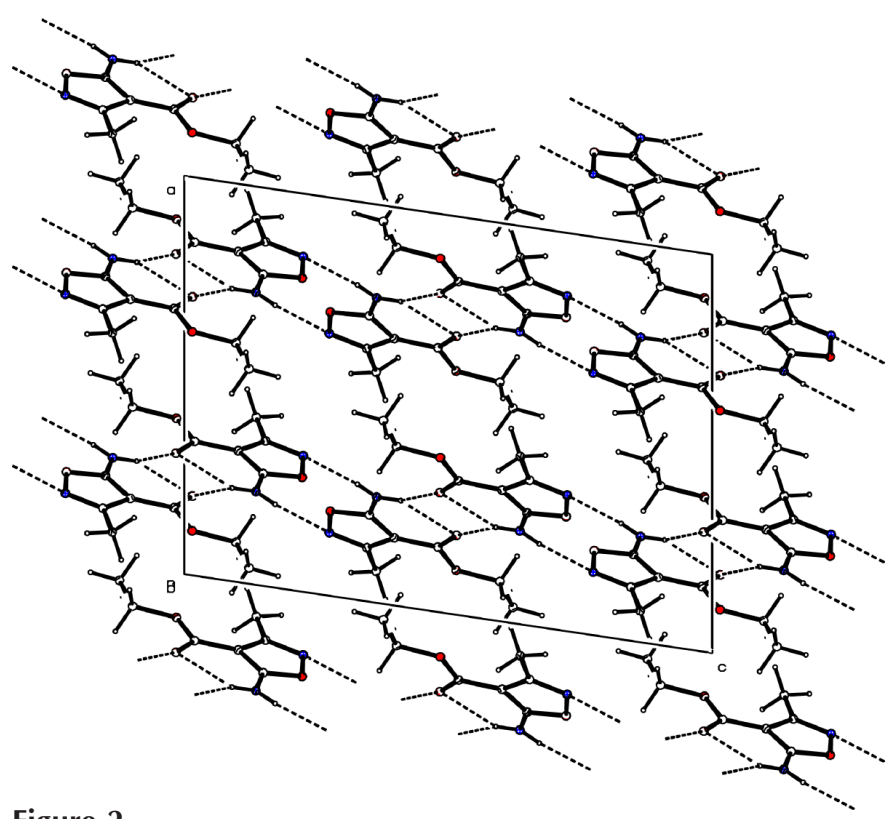

Figure 2

A packing diagram of the crystal structure, viewed down the $b$ axis. Dashed lines represent hydrogen bonds.

SMMS acknowledges the Council of Scientific and Industrial Research for financial support.

\section{References}

Bernstein, J., Davis, R. E., Shimoni, L. \& Chang, N-L. (1995). Angew. Chem. Int. Ed. Engl. 34, 1555-1573.

Farrugia, L. J. (1997). J. Appl. Cryst. 30, 565.

Giranda,V. L. (1995). Acta Cryst. D51, 496-503.

Liu, B., Liu, G., Xin, Z., Serby, M. D., Zhao, H., Schaefer, V. G., Falls, H. D., Kaszubska, W., Collins, C. A. \& Sham, H. L. (2004). Bioorg. Med. Chem. Lett. 14, 5223-5226. 


\section{organic papers}

Shankar, B. B., Yang, D. Y., Girton, S. \& Ganguly, A. K. (1998). Tetrahedron Lett. 39, 2447-2448.

Sheldrick, G. M. (1997). SHELXS97 and SHELXL97. University of Göttingen, Germany.

Siemens (1996). SAINT and SMART. Siemens Analytical X-ray Systems, Inc., Madison, Wisconsin, USA.

Skolnick, P. (2002). J. Clin. Psychiatry, 63 (Suppl. 2), 19-23.
Spek, A. L. (2003). J. Appl. Cryst. 36, 7-13.

Zhao, H., Liu, G., Xin, Z., Serby, M. D., Pei, Z., Szczepankiewicz, B. G., Hajduk, P. J., Abad-Zapatero, C., Hutchins, C. W., Lubben, T. H., Ballaron, S. J., Haasch, D. L., Kaszubska, W., Rondinone, C. M., Trevillyan,

J. M. \& Jirousek, M. R. (2004). Bioorg. Med. Chem. Lett. 14, 55435546.

Zsolnai, L. (1998). ZORTEP. University of Heidelberg, Germany. 